\title{
Vascular Smooth Muscle Cell Proliferation is Effectively Suppressed by the Non-specific Growth Factor Inhibitor Suramin
}

\author{
Kazushi Urasawa, *MD, Satoshi KaneTA, MD, Noritsugu NAKANO, MD, \\ Takahiko SAITO, MD, Hidetsugu SAKAI, MD, Chika TAKAGI, MD, \\ Yasushi TAKAGI, MD, Hiroyuki SugIKI, MD, and Akira KITABATAKE, MD
}

\begin{abstract}
SUMMARY
The purpose of this study was to investigate the effects of the non-specific growth factor inhibitor suramin on smooth muscle cell proliferation in vitro and in vivo. Cultured vascular smooth muscle cells (VSMC) were stimulated by platelet-derived growth factor (PDGF) and cellular DNA synthesis assessed by $\left[{ }^{3} \mathrm{H}\right]$-thymidine uptake. Suramin dosedependently inhibited DNA synthesis in VSMC, and $100 \mu \mathrm{M}$ of suramin completely suppressed the PDGF-AB-induced cellular DNA synthesis. Rabbit carotid arteries were injured by the balloon catheter, and then suramin locally delivered using a porous balloon catheter over ten minutes. Three weeks after the vascular injury, the extent of intimal thickening was compared between the suramin-treated and control rabbits. The neointimal formation triggered by balloon-mediated vascular injury was suppressed significantly and dose-dependently by locally infused suramin, and the intima to media area ratios of the control and $1 \mathrm{mM}$ suramin-treated animals were $48.8 \pm 14.9$ and $12.2 \pm 6.0 \%$, respectively ( $p<0.01$. $n=6$ for each group). These results suggest that one time local administration of suramin was sufficient to suppress neointimal formation after balloonmediated vascular injury, and that pharmacological intervention targeting the growth factor's signaling pathways could be a promising approach to prevent smooth muscle cell proliferation in various proliferative vascular diseases. (Jpn Heart J 2001; 42: 221-233)
\end{abstract}

Key words: Suramin, Smooth muscle cell, Restenosis, Growth factors, Local drug delivery

Percutaneous transluminal coronary angioplasty (PTCA) is a widely performed and indispensable technique for treating patients with ischemic heart diseases such as angina pectoris and acute myocardial infarction. However, a major limitation of this powerful technique is the fact that roughly $40 \%$ of patients

\footnotetext{
From the Department of Cardiovascular Medicine, Hokkaido University School of Medicine, Sapporo, Hokkaido 060-8636, Japan.

* Supported in part by a research grant from the Takeda Medical Research Foundation.

Address for correspondence: Kazushi Urasawa, MD, Department of Cardiovascular Medicine, Hokkaido University Graduate School of Medicine, Kita 15, Nishi 7, Kita-ku, Sapporo, Hokkaido 060-8636, Japan.

Received for publication September 13, 2000.

Revised and accepted October 7, 2000. 
undergoing PTCA develop coronary restenosis, the recurrence of stenosis at the site of angioplasty several months after the procedure. ${ }^{1)}$ It is well known that coronary restenosis is composed of several independent vascular events such as elastic recoil, vascular remodeling and smooth muscle cell (SMC) proliferation. Intra-coronary stents have proven to be effective to reduce the coronary restenosis caused by elastic recoil and chronic vascular remodeling. The restenosis rate after stenting, however, is still as high as $20 \%{ }^{2}{ }^{2}$ In these stent cases, SMC proliferation is the major cause of restenosis.

Various growth factors and cytokines play pivotal roles in the process of coronary restenosis, which includes SMC migration, proliferation, and extracellular matrix production from SMC. ${ }^{3)}$ In general, growth factors and cytokines are recognized by cell surface receptors, and the activated receptors then trigger several intracellular signaling cascades, finally resulting in DNA replication and cell division. ${ }^{4)}$ Any point within this signaling cascade can be a target for preventing SMC growth in the setting of coronary restenosis. Based on this hypothesis, we investigated the effects of suramin, a potent anti-growth factor agent with a broad spectrum, on SMC proliferation after growth stimulation.

\section{Materials AND Methods}

Suramin, 8,8'-[Carbonylbis [imino-3,1-phenylenecarbonylimino (4-methyl3,1-phenylene) carbonylimino]] bis-1,3,5-naphthalenetrisulfonic acid hexasodium salt, was obtained from Bayer (Leverkusen, Germany). Fetal bovine serum (FBS), Dulbecco's Modified Eagle Medium (DMEM) and other cell culture media were purchased from Gibco BRL (Rockville MD, USA). Three isoforms of platelet-derived growth factor (PDGF), $\mathrm{AA}, \mathrm{AB}$ and $\mathrm{BB}$, were purchased from Boehringer Mannheim (Germany). 3H-thymidine $(1 \mathrm{mCi} / \mathrm{m} l)$ was purchased from DuPont NEN (Boston, MA, USA). A10 cells were obtained from the American Type Tissue Collection.

Cell isolation and culture: A10 cells, an established smooth muscle cell line which originated from rat abdominal aorta, were maintained in DMEM supplemented with $10 \% \mathrm{FBS}, 100 \mu \mathrm{g} / \mathrm{m} l$ penicillin and $100 \mu \mathrm{g} / \mathrm{m} l$ streptomycin. The A10 cells used in this study were those maintained for less than 60 days. In order to establish the primary culture of rat vascular SMC (RVSMC), abdominal aortae were excised from male Wistar rats (250-400 gram body weight), dissected into small pieces (about $1 \mathrm{~mm}$ in length), and then placed on tissue culture dishes containing DMEM supplemented with 20\% FBS. Two to three weeks after the tissue preparation, aortic rings were removed from the dishes, and the RVSMC grown from dissected tissues were passaged by trypsinization. All experiments on RVSMC were performed between passages 3 to 6 . 
Treatment of vascular smooth muscle cells with suramin: A10 or RVSMC were cultured in DMEM supplemented with 10\% FBS until the cellular density reached $50 \%$. The culture medium was then changed to DMEM containing $0.5 \%$ FBS, and maintained for 48 (or 24) hours in order to synchronize the cell-cycle to G0 / 1 phase. The synchronized cells were stimulated either by $10 \mathrm{ng} / \mathrm{m} l$ PDGFAA, PDGF-AB, PDGF-BB or $2 \%$ FBS for 24 hours. PDGF- or serum-stimulated DNA synthesis was assessed by measuring $\left[{ }^{3} \mathrm{H}\right]$-thymidine uptake as follows. After growth stimulation by PDGF or serum, the cells were washed twice with DMEM and then incubated with DMEM containing $1 \mu \mathrm{Ci} / \mathrm{ml}\left[{ }^{3} \mathrm{H}\right]$-thymidine for one hour. These cells were fixed in $6 \%$ trichloroacetic acid at $4^{\circ} \mathrm{C}$ for 12 hours, treated with $1 \mathrm{~N} \mathrm{NaOH}$ at $37^{\circ} \mathrm{C}$ for 1 hour, and then neutralized by adding $6 \mathrm{~N}$ $\mathrm{HCl}$. The extracted radioactivity was measured with a liquid scintillation counter.

Animal model of neointimal formation: Japanese white rabbits (weighing 2.5 to $3.0 \mathrm{~kg}$ ) were anesthetized with sodium pentobarbital ( $25 \mathrm{mg} / \mathrm{kg}$, intravenously) and a $7 \mathrm{~cm}$ long catheter introducer sheath (4F Super-sheath ${ }^{\circledR}$, Medikit, Japan) introduced into the right femoral artery. A 0.014 inch guide wire (High-Torque Floppy $\mathrm{II}^{\circledR}$, ACS, Temecula, USA) was then advanced to the right common carotid artery through the catheter introducer sheath under fluoroscopic guidance. A coronary angioplasty balloon catheter (diameter: $3 \mathrm{~mm}$, length: $10 \mathrm{~mm}, \mathrm{ACX}-$ $\mathrm{II}^{\circledR}$, ACS, Temecula, USA) was then advanced over the guide wire to the distal end of the right common carotid artery and inflated at 120 psi. The endothelial layer of the common carotid artery was denuded by three passes of the inflated balloon. In order to define the treated area at a later time point, the balloon-mediated endothelial denudation was created on the vascular segment between two anatomical markers, the lower edge of the mandibula and the upper edge of the right subclavia, under the fluoroscopic guide.

Local delivery of suramin in the animal model: After the balloon-mediated vascular endothelial denudation, an angioplasty balloon catheter was changed to a porous balloon catheter (Transport ${ }^{\circledR}$, Cardio Vascular Dynamics Inc., Irvine, CA, USA). This catheter is composed of dual balloons which are located within one another; an inner dilating balloon and an outer infusion balloon. The outer infusion balloon has forty-eight small pours ( $250 \mu \mathrm{m}$ in diameter) circumferentially across $10 \mathrm{~mm}$ of its mid section to permit regional infusion of various pharmacological agents. At the site of endothelial denudation, the inner balloon was inflated with $90 \mathrm{psi}$ and then the pressure reduced to $15 \mathrm{psi}$. Suramin dissolved in $5 \%$ glucose was injected through the drug delivery channel of the Transport ${ }^{\circledR}$ catheter at a constant infusion rate of $30 \mathrm{ml} /$ hour over 10 minutes using an automatic infusion pump. Two different concentrations of suramin solution $(0.5 \mathrm{mM}$ and $1.0 \mathrm{mM}$ ) were injected into three (low dose group) and six rabbits (high dose group), respectively. In another six rabbits, 5\% glucose was injected in the same 
manner (control group). All experimental protocols for the animal studies were approved by the Animal Care Committee of the Institute for Animal Experimentation, Hokkaido University School of Medicine (Sapporo, Japan).

Evaluation of Intimal Hyperplasia: Three weeks after the procedure, arterial segments between the two anatomical markers (mandibula and subclavia) were excised, washed with PBS, and fixed in $8 \%$ formaldehyde. Vascular segments (1 $\mathrm{cm}$ in length) were excised from the middle portion of each carotid artery and then subdivided into five segments of about $2 \mathrm{~mm}$ in length. All tissue sections were stained by Elastica Van Gieson staining. The microscopic images of each transverse tissue section were digitized, the borders of the vessel layers manually traced, and then the intima to media area ratio (IMAR) calculated using an imageprocessing software (NIH Image). The mean IMAR from five consecutive transverse tissue sections was used as the representative IMAR in each animal.

Data presentation and statistical analysis: All data are expressed as mean $\pm \mathrm{SD}$ and were analyzed by unpaired $t$-test. Because of the limited number of low dose group animals, the $t$-test was used instead of one-way ANOVA. A difference was accepted as statistically significant when the $p$ value was less than 0.05 .

\section{RESULTS}

Effect of suramin on vascular smooth muscle cells: A10 cells were cultured in DMEM containing $0.5 \%$ FBS for 48 hours in order to synchronize the cell-cycle to G0 / 1 phase. Preliminary experiments revealed that complete removal of FBS rapidly decreased the cell viability (data not shown). Synchronized A10 cells were stimulated by either $10 \mathrm{ng} / \mathrm{m} l$ PDGF-AB or $2 \%$ FBS in the presence of various concentrations of suramin $(0$ to $400 \mu \mathrm{M})$ for 24 hours and then DNA synthesis assessed by $\left[{ }^{3} \mathrm{H}\right]$-thymidine uptake. The DNA synthesis stimulated by $2 \%$ FBS was partially inhibited by high concentrations of suramin. On the other hand, PDGF-AB stimulated DNA synthesis was inhibited by suramin significantly and dose-dependently. The $\mathrm{IC}_{50}$ of suramin for PDGF-AB-stimulated DNA synthesis was $80 \mu \mathrm{M}$ from the dose-response experiments (Figure 1). The inhibitory effect of suramin on DNA synthesis was closely correlated with the incubation time. Longer incubation with suramin resulted in more significant inhibition of DNA synthesis in A10 cells. The inhibition of DNA synthesis in the cells incubated with $100 \mu \mathrm{M}$ suramin for 90 minutes was about $60 \%$ of that observed in the cells exposed to suramin for 24 hours (Figure 2). The inhibitory effect of suramin on DNA synthesis was linearly correlated with incubation times up to 90 minutes (Figure 2 inset). In order to investigate the isoform specificity of the anti-PDGF activity of suramin, A10 cells were stimulated either by $2 \% \mathrm{FBS}, 10 \mathrm{ng} / \mathrm{ml}$ PDGF-AA, $10 \mathrm{ng} / \mathrm{m} l$ PDGF-AB or $10 \mathrm{ng} / \mathrm{m} l$ PDGF-BB for 24 hours with (or 


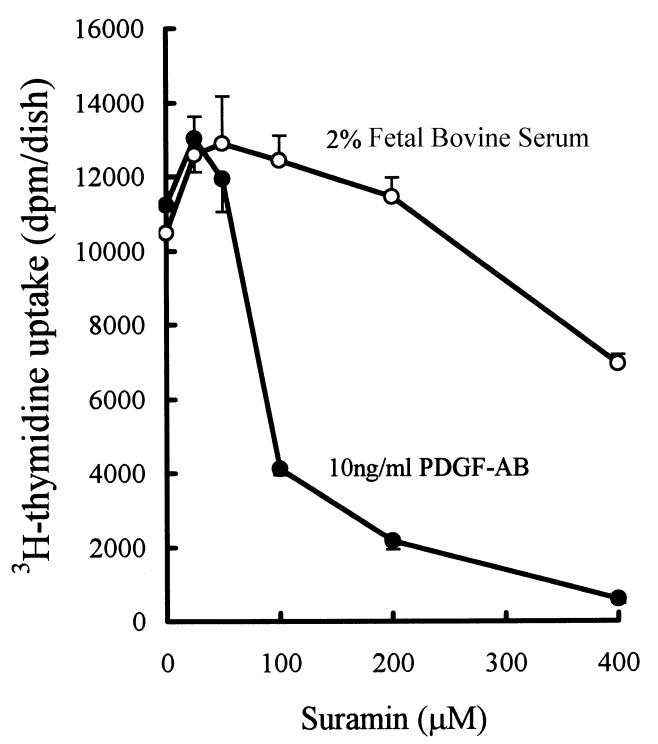

Figure 1. Effect of suramin on serum- or PDGF-stimulated DNA synthesis in A10 cells. A10 cells were synchronized to G0 / 1 by serum deprivation for 48 hours and then stimulated by Dulbecco's Modified Eagle Medium (DMEM) supplemented with 2\% fetal bovine serum or DMEM containing $10 \mathrm{ng} / \mathrm{m} l$ PDGF-AB for 24 hours in the presence of various concentrations of suramin. DNAsynthesis in A10 cells was assessed by ${ }^{3} \mathrm{H}$-thymidine uptake. Each point represents the mean value of four different experiments.

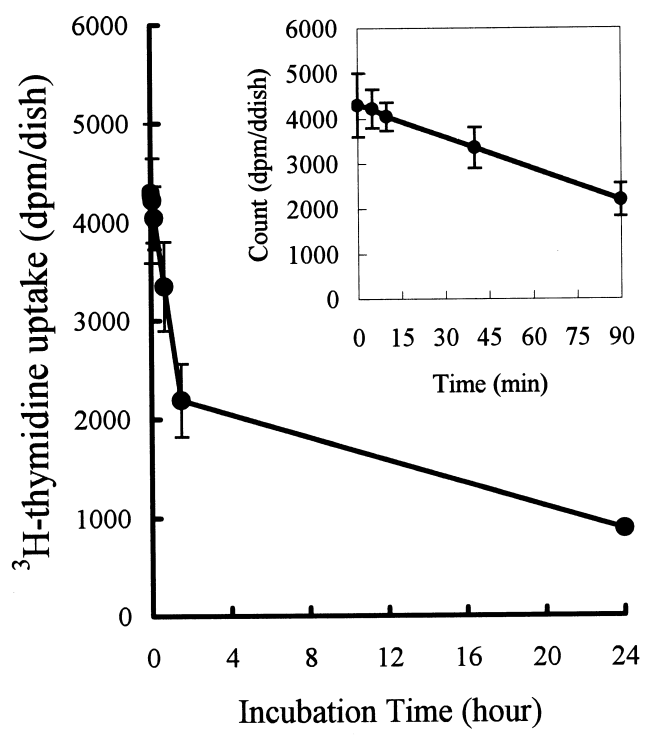

Figure 2. Time-dependency of the inhibitory effect of suramin on PDGF-stimulated DNA synthesis in A10 cells. A10 cells were synchronized to G0 / 1 by serum deprivation for 48 hours and then stimulated by Dulbecco's Modified Eagle Medium (DMEM) containing $10 \mathrm{ng} / \mathrm{m} l$ PDGF-AB and $100 \mu \mathrm{M}$ suramin for 24 hours. At the indicated time points, the medium was changed to DMEM containing PDGF-AB only and then incubation was carried out for the rest of the stimulation period. The duration of the stimulation period was adjusted to 24 hours in all conditions. DNA-synthesis in A10 cells was assessed by ${ }^{3} \mathrm{H}$-thymidine uptake. The inset shows data at early time points. Each point represents the mean $\pm \mathrm{SD}$ of four different experiments.

without) $100 \mu \mathrm{M}$ suramin. Among the three PDGF isoforms, PDGF-BB provoked the highest DNA synthesis in A10 cells, which was almost comparable to that induced by $2 \%$ FBS. On the contrary, the extent of PDGF-AA-stimulated DNA synthesis was very low in A10 cells. Although inhibition of DNA synthesis was statistically significant in all cases, suramin suppressed the PDGF-ABinduced DNA synthesis far more efficiently than those provoked by the other two PDGF isoforms (Figure 3). RVSMC were also arrested in G0 / 1 by serum deprivation for 24 hours and then stimulated either by $2 \%$ FBS or $10 \mathrm{ng} / \mathrm{ml}$ PDGF isoforms for 24 hours in the presence (or absence) of $100 \mu \mathrm{M}$ suramin. PDGFAA- and PDGF-AB-induced DNA syntheses were significantly inhibited by suramin. FBS-induced DNA synthesis of RVSMC was also suppressed by 


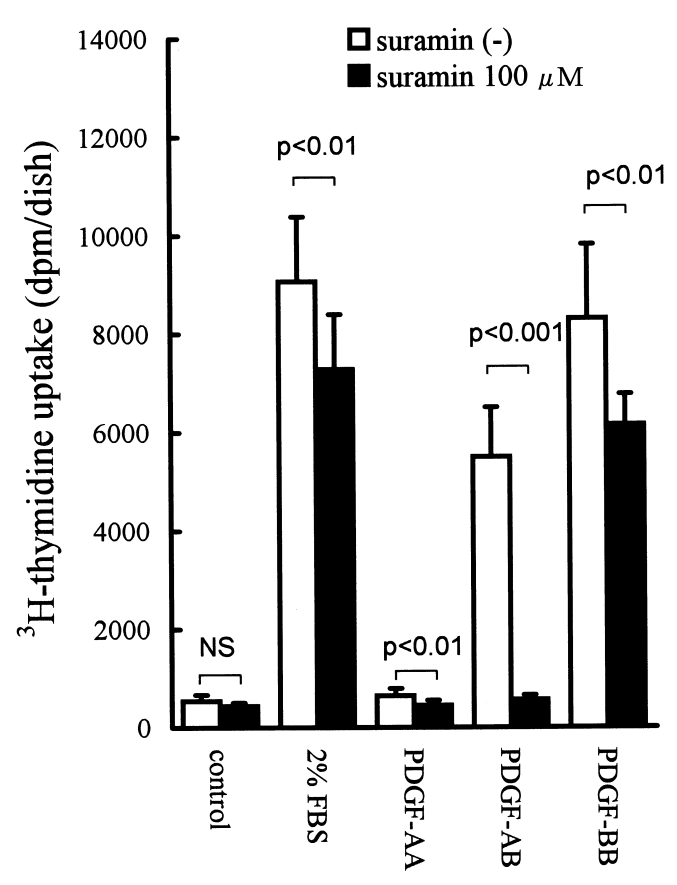

Figure 3. Inhibitory effect of Suramin on DNA synthesis in A10 cells. A10 cells were synchronized to G0 / 1 by serum deprivation for 48 hours and then stimulated by Dulbecco's Modified Eagle Medium (DMEM) containing $2 \%$ fetal bovine serum, $10 \mathrm{ng} / \mathrm{ml}$ PDGF-AA, $10 \mathrm{ng} / \mathrm{m} l$ PDGF-AB or $10 \mathrm{ng} / \mathrm{m} l$ PDGF-BB, respectively, for 24 hours with (or without) $100 \mu \mathrm{M}$ suramin. DNA synthesis in $\mathrm{A} 10$ cells was assessed by ${ }^{3} \mathrm{H}$-thymidine uptake. Each bar represents the mean $\pm \mathrm{SD}$ of eight different experiments.

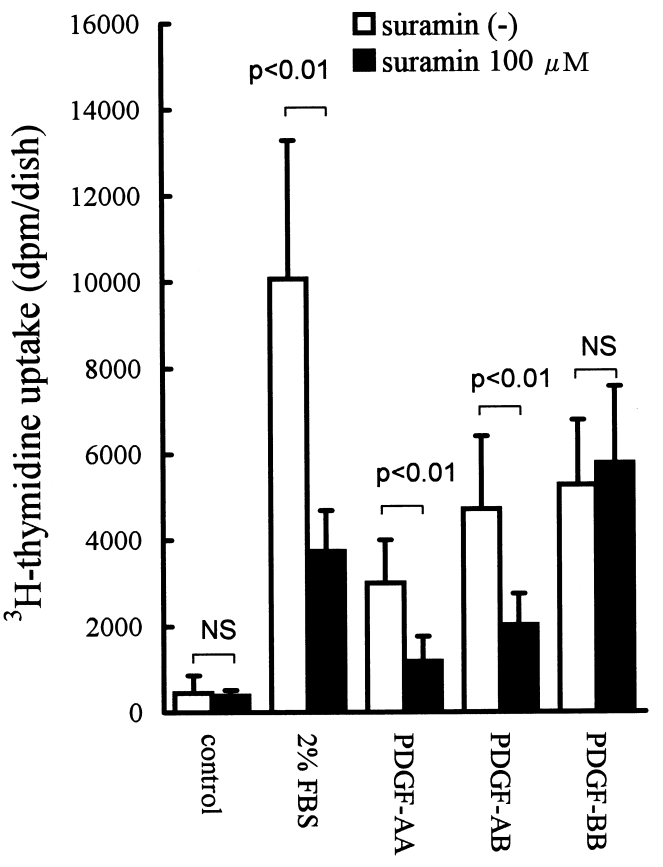

Figure 4. Inhibitory effect of Suramin on DNA synthesis in primary cultures of rat vascular smooth muscle cells. Rat vascular smooth muscle cells obtained by an explant method were synchronized to G0 / 1 by serum deprivation for 24 hours, and then stimulated by Dulbecco's Modified Eagle Medium (DMEM) containing either $2 \%$ fetal bovine serum, $10 \mathrm{ng} / \mathrm{m} l$ PDGF-AA, $10 \mathrm{ng} / \mathrm{m} l$ PDGF-AB or $10 \mathrm{ng} / \mathrm{m} l$ PDGF-BB for 24 hours with (or without) $100 \mu \mathrm{M}$ suramin. DNA synthesis was assessed by ${ }^{3} \mathrm{H}$-thymidine uptake. Each bar represents the mean \pm SD of eight different experiments.

suramin (Figure 4).

Inhibition of intimal hyperplasia by suramin: Three weeks after balloon-mediated vascular injury, the common carotid arteries of the control rabbits showed significant intimal hyperplasia in which the neointimal layer had a thickness comparable to that of the medial layer. Histological examination revealed that one time local infusion of suramin significantly inhibited neointimal formation at the site of vascular injury (Figures 5 and 6). Suramin dose-dependently inhibited neointimal formation after vascular injury. The intima to media area ratios of the control, $0.5 \mathrm{mM}$ suramin, and $1.0 \mathrm{mM}$ suramin groups were $48.8 \pm 14.9 \%, 21.0 \pm$ $12.0 \%$ and $12.2 \pm 6.0 \%$, respectively ( $p<0.05$ for control group vs. low dose group, $p<0.01$ for control group vs high dose group) (Figure 7). 


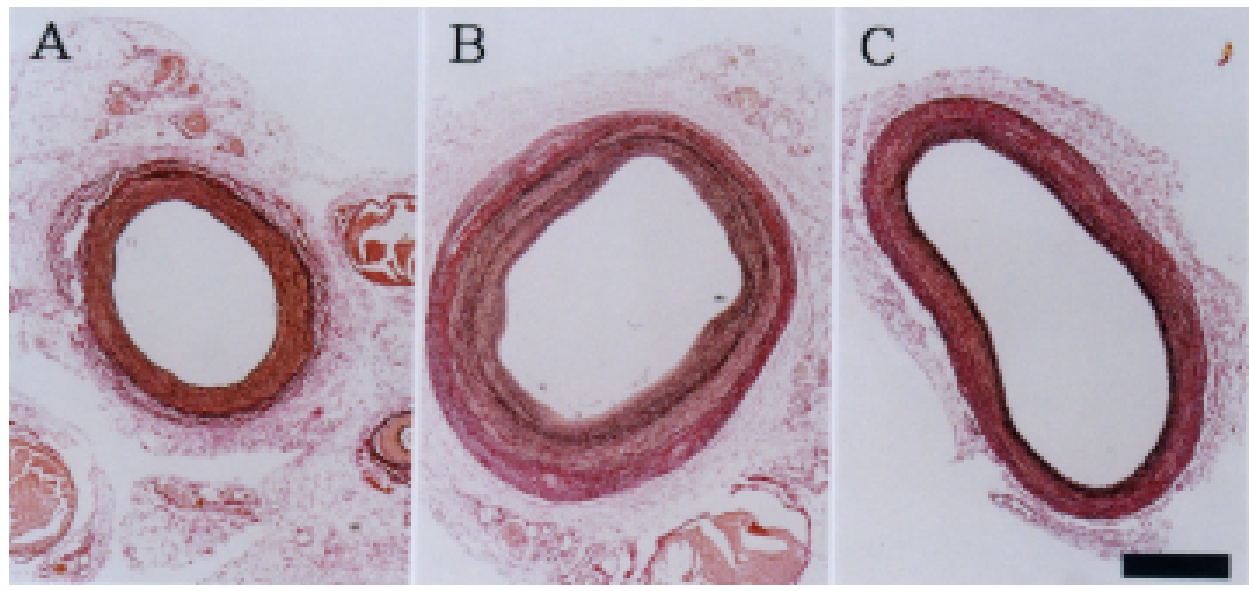

Figure 5. Representative histological sections of rabbit common carotid arteries 3 weeks after balloon-mediated vascular injury (Low magnification). Elastica Van Gieson staining of representative section of rabbit carotid arteries. A: Control carotid artery without denudation. B: Balloon injured rabbit carotid artery treated with $5 \%$ glucose. C: Balloon injured carotid artery treated with $1 \mathrm{mM}$ suramin. Black bar indicates $500 \mu \mathrm{m}$.

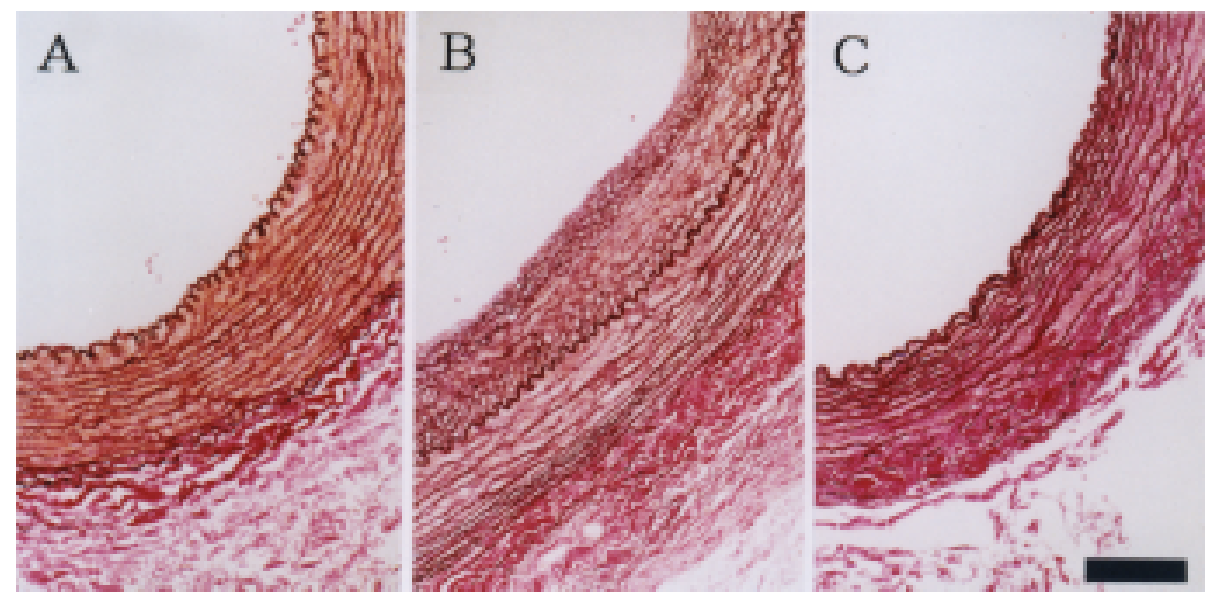

Figure 6. Representative histological sections of rabbit common carotid arteries 3 weeks after balloon-mediated vascular injury (High magnification). Representative sections of rabbit carotid arteries with higher magnification. A: Control rabbit. B: $5 \%$ glucose. C: $1 \mathrm{mM}$ injection of suramin. Black bar indicates $100 \mu \mathrm{m}$. 


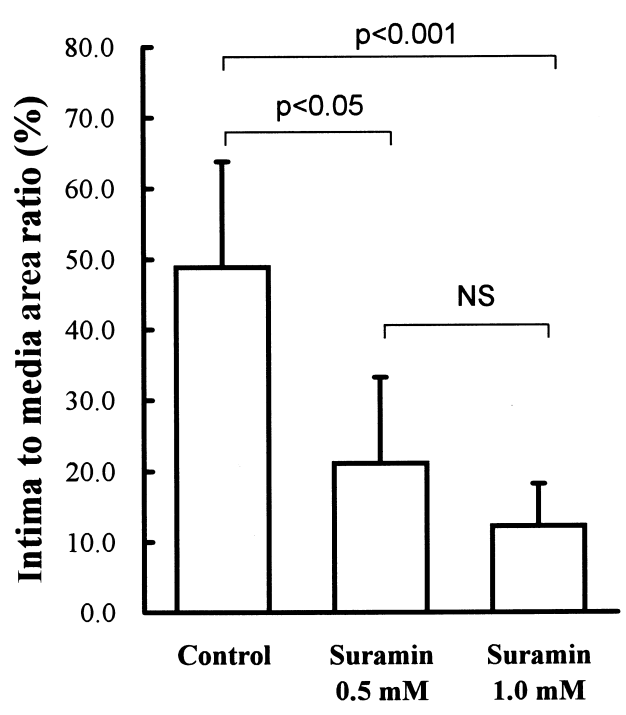

Figure 7. Quantitative analysis of the suramin-mediated suppression of intimal thickening after vascular injury. Photographs of tissue sections were digitized and the extent of neointimal formation was analyzed using image processing software. Intimal hyperplasia was expressed as the intima to media area ratio. Each bar represents the mean + SD of six (control and $1 \mathrm{mM}$ suramin group) or three ( $0.5 \mathrm{mM}$ suramin group) rabbits.

\section{DISCUSSION}

Despite rapid progress in the field of coronary intervention devices, the restenosis rate after catheter-based coronary angioplasty remains high. In fact, nearly $40 \%$ of patients treated by balloon angioplasty alone exhibit angiographical restenosis, and roughly half of them require target lesion revascularization either by re-intervention or coronary artery bypass surgery. ${ }^{5)}$ To date, various pharmacological drugs such as anti-platelet drugs, $\mathrm{Ca}$ antagonists, angiotensin converting enzyme inhibitors, lipid lowering drugs and steroids have been used in anticipation of their preventive effect against coronary restenosis. ${ }^{5-10)}$ Although most of these drugs suppress SMC proliferation in vitro and some prevent intimal thickening after vascular injury in vivo, all but a few have failed to demonstrate a clinical benefit. ${ }^{11-13)}$ Because previous investigations using atherosclerotic plaques from human coronary arteries have shown that SMC and the extracellular matrix are the major components of restenotic tissue, ${ }^{14)}$ SMC proliferation should be targeted to prevent coronary restenosis. Coronary restenosis is, however, a 
fairly complex biological process. A wide variety of growth factors and cytokines, such as PDGF, transforming growth factor $\beta$ (TGF $\beta$ ), and epidermal growth factor (EGF), are responsible for the migration and proliferation of SMC. ${ }^{15)}$

The polyanionic compound suramin was originally designed as a drug for treating trypanosomiasis and onchoceriasis. ${ }^{16)}$ It is well known that suramin is a unique anti-growth factor agent with a broad spectrum. PDGF, EGF, TGF $\beta$, basic fibroblast growth factor (bFGF), insulin-like growth factor and interleukin-6 (IL6) are known to be inhibited by suramin. ${ }^{17-21)}$ Several key enzymes are also suppressed by suramin, including protein kinase $\mathrm{C}$, phosphatidylinositol kinase, diacylglycerol kinase, DNA polymerase, DNA topoisomerase II, and reverse transcriptase. ${ }^{22-26)}$ These unique pharmacological properties may be the reason why suramin has shown an antiproliferative effect on a variety of human cancer cell lines, such as those obtained from rhabdomyosarcoma, multiple myeloma, prostate cancer and breast cancer. ${ }^{27-30)}$ Thus, the pharmacological characteristics of suramin seem to be suitable for the prevention of SMC proliferation after vascular injury, a complex cellular response consisting of receptor activation, intracellular signaling and DNA replication.

In this study, we examined the antiproliferative effect of suramin utilizing two different experimental settings; (I) cultured vascular smooth muscle cells and (II) a rabbit vascular injury model. PDGF-stimulated DNA synthesis of SMC was inhibited by suramin significantly and dose-dependently, and its $\mathrm{IC}_{50}$ was calculated to be $80 \mu \mathrm{M}$ (Figure 1). A previous report using radioactive PDGF ligands revealed that the $\mathrm{IC}_{50}$ of suramin for the binding of PDGF with its receptor was 60 $\mu \mathrm{M}$, which is comparable to the value obtained in our experiments. ${ }^{31)}$ Interestingly, a weak growth stimulatory effect was observed at a relatively low concentration $(25 \mu \mathrm{M})$ of suramin, though the increase in cellular DNA synthesis at this concentration was not statistically significant. Such a pleiotropic action for suramin was also reported previously in an experiment using cancer cells. ${ }^{32)}$ It has been suggested that a low concentration of suramin could release membranebound transforming growth factor $\alpha(\mathrm{TGF} \alpha)$ and increase its potential to activate cell surface epidermal growth factor receptors. ${ }^{33)}$ Because of such a pleiotropic action, it would be appropriate to maintain relatively high concentrations of suramin at the site of action. The dose-response experiment suggested that higher local concentrations of suramin could provide a better antiproliferative effect when suramin was used in in vivo situations. Although there are several reports suggesting suramin has a non-specific cytotoxic effect, the structural features of A10 cells, such as cell size, cell shape and perinuclear structures, were not altered during the experiments, even at the highest concentration of suramin (400 $\mu \mathrm{M})$ used in the present study. 
In order to assess the temporal profile of the antiproliferative effect of suramin, A10 cells were incubated with $10 \mathrm{ng} / \mathrm{m} l$ PDGF-AB and $100 \mu \mathrm{M}$ suramin for various lengths of time. At the indicated time points, the culture media were changed to those containing only PDGF-AB, and growth stimulation was continued for the rest of the incubation period. The entire stimulation period was adjusted to 24 hours in all conditions. As shown in Figure 2, the inhibition of PDGF-stimulated DNA synthesis was strictly dependent on the length of time of incubation with suramin. The inhibition of DNA synthesis observed at 90 minutes exposure to suramin was $60 \%$ of that observed in the cells exposed to suramin for the entire 24 hours. Interestingly, the anti-proliferative effect of suramin was linearly correlated with incubation times up to 90 minutes (Figure 2 inset). This finding clearly suggests that longer exposure to suramin may provide more significant inhibition of cellular DNA synthesis.

It has been reported that suramin directly interacts with PDGF molecules since suramin inhibited the interaction between PDGF and anti-PDGF antibody. ${ }^{31)}$ In our experiments, suramin inhibited PDGF-AB-induced growth stimulation much more effectively than PDGF-BB-induced growth stimulation (Figures 3 and 4), suggesting that suramin may have a higher affinity for the PDGF-A chain than the PDGF-B chain. It has been reported that established cell lines show different responses to various physiological stimuli compared to primary culture cells, even though they originated from the same tissue. Thus, we tested the effect of suramin using explanted rat aortic SMC (RVSMC). The DNA synthesis triggered by PDGF-AA and PDGF-AB was significantly inhibited by suramin in RVSMCs. On the other hand, PDGF-BB-stimulated DNA synthesis was not affected by suramin. These data also suggest that suramin exhibits a preference for the PDGF-A chain. In RVSMCs, PDGF-AA elicited a more prominent response than A10 cells, which may suggest a distinctive receptor subtype composition in each cell. Serum-induced DNA synthesis was suppressed by suramin more effectively in RVSMC than in A10 cells, indicating different serum-dependencies for these cell lines (Figures 3 and 4).

Balloon-mediated removal of the endothelial layer from rabbit carotid arteries promoted significant intimal thickening three weeks after the endodenudation procedure. Histological examination proved that the neointima was composed of pure smooth muscle cells and that these rabbits were an appropriate model of human coronary restenosis (Figure $5 \mathrm{~b}, 6 \mathrm{~b}$ ). In this study, a porous balloon catheter was used for the local delivery of suramin in order to maintain a high local suramin concentration, and at the same time to reduce the total amount of suramin. Based on the findings obtained from in vitro experiments, we used 0.5 $\mathrm{mM}$ and $1.0 \mathrm{mM}$ suramin solutions and a 10 minute incubation period. Because blood flow was completely interrupted during balloon inflation, the local concen- 
tration of suramin was expected to be almost the same as that of the infused solution. As shown in Figure 7, neointimal formation after vascular injury was inhibited by suramin significantly and dose-dependently. The intima to media area ratio in the high dose group was about $25 \%$ of that in the control group. It has been reported that intravenous injection of suramin attenuates neointimal formation in the rabbit abdominal aorta after the indwelling of polyethylene tubing for 24 hours. $^{34)}$ Balloon-mediated endothelial denudation might be a more appropriate means with which to mimic the vascular injury caused by the PTCA procedure. In addition, suramin was delivered using a local drug-delivery catheter in our study. Local drug delivery is advantageous for reducing the total amount of suramin, and at the same time, maintaining high local drug concentrations at the target lesion. More recently, Gary, et al. reported that chronic infusion of suramin inhibited neointimal formation in rabbit iliac arteries after balloon injury. ${ }^{35)}$ It should be emphasized that, in our study, one time administration of suramin was shown to be sufficient to inhibit neointimal formation after balloon injury.

Through many pharmacokinetic studies in human trypanosomiasis patients, it has been reported that suramin is tightly bound to plasma proteins (mostly serum albumin) and has a strikingly long elimination half-life, about 36 days. $^{36}$ ) The most common side effects of suramin are polyneuropathy, allergic skin rash and renal dysfunction, while rare side effects include agranulocytosis, hemolytic anemia and shock. Because most of these side effects are dose-dependent, a local drug delivery regimen should be helpful at minimizing the toxicity of this type of drug. Although the in vivo localization of suramin is still controversial, based on a previous report, some of the locally delivered suramin may accumulate in vascular endothelial cells and presumably in underlying vascular smooth muscle cells. $^{37)}$

In summary, the anti-growth factor agent suramin significantly inhibited DNA synthesis in cultured vascular smooth muscle cells. Moreover, one time local infusion of suramin significantly suppressed the neointimal formation after vascular injury in an animal model. These results clearly suggested that pharmacological intervention targetting the signaling pathway of the growth factor would be a promising and practical approach for preventing SMC proliferation.

\section{REFERENCES}

1. Kuntz RE, Baim DS. Defining coronary restenosis. Newer clinical and angiographic paradigms. Circulation 1993; 88: 1310-23.

2. Erbel R, Haude M, Hopp HW. Coronary-artery stenting compared with balloon angioplasty for restenosis after initial balloon angioplasty. Restenosis Stent Study Group. N Engl J Med 1998; 339:1672-8.

3. Libby P, Schwartz D, Brogi E, Tanaka H, Clinton SK. A cascade model for restenosis: a special case of atherosclerosis progression. Circulation 1992; 86(6 Suppl): III47-III52. 
4. Seger R, Krebs EG. The MAPK signaling cascade. FASEB J 1995; 9: 726-35.

5. Schwartz L, Bourassa MG, Lesperance J, et al. Aspirin and dipyridamole in the prevention of restenosis after percutaneous transluminal coronary angioplasty. N Engl J Med 1988; 318: 1714-9

6. Schwartz L, Lesperance J, Bourassa MG, et al. The role of antiplatelet agents in modifying the extent of restenosis following percutaneous transluminal coronary angioplasty. Am Heart J 1990; 119: 232-6.

7. Hoberg E, Kubler W. Prevention of restenosis after PTCA: role of calcium antagonists. J Cardiovasc Pharmacol 1991; 18 Suppl 6: S15-S19.

8. Faxon DP. Effect of high dose angiotensin-converting enzyme inhibition on restenosis: final results of the MARCATOR Study, a multicenter, double-blind, placebo-controlled trial of cilazapril. The Multicenter American Research Trial With Cilazapril After Angioplasty to Prevent Transluminal Coronary Obstruction and Restenosis (MARCATOR) Study Group. J Am Coll Cardiol 1995; 25: 362-9.

9. Bertrand ME, McFadden EP, Fruchart JC, et al. Effect of pravastatin on angiographic restenosis after coronary balloon angioplasty. The PREDICT Trial Investigators. Prevention of Restenosis by Elisor after Transluminal Coronary Angioplasty. J Am Coll Cardiol 1997; 30: 863-9.

10. Pepine CJ, Hirshfeld JW, Macdonald RG, et al. A controlled trial of corticosteroids to prevent restenosis after coronary angioplasty. M-HEART Group. Circulation 1990; 81: 1753-61.

11. Kosuga K, Tamai H, Ueda K, et al. Effectiveness of tranilast on restenosis after directional coronary atherectomy. Am Heart J 1997; 134: 712-8.

12. Maresta A, Balducelli M, Cantini L, et al. Trapidil (triazolopyrimidine), a platelet-derived growth factor antagonist, reduces restenosis after percutaneous transluminal coronary angioplasty. Results of the randomized, double-blind STARC study. Studio Trapidil versus Aspirin nella Restenosi Coronarica. Circulation 1994; 90: 27105 .

13. Tardif JC, Cote G, Lesperance J, et al. Probucol and multivitamins in the prevention of restenosis after coronary angioplasty. Multivitamins and Probucol Study Group. N Engl J Med 1997; 337: 365-72.

14. Libby P, Schwartz D, Brogi E, Tanaka H, Clinton SK. A cascade model for restenosis. A special case of atherosclerosis progression. Circulation 1992; 86(6 Suppl): III47-III52.

15. Ross R. The pathogenesis of atherosclerosis: a perspective for the 1990s. Nature 1993; 362: 801-9.

16. Hawking F. Suramin: With special reference to onchocerciasis. Adv Phramacol Chemother 1978; 15: 289-322.

17. Hosang M. Suramin binds to platelet-derived growth factor and inhibits its biological activity. J Cell Biochem 1985; 29: 265-73.

18. Coffey RJ Jr, Leof EB, Shipley GD, Moses HL. Suramin inhibition of growth factor receptor binding and mitogenicity in AKR-2B cells. J Cell Physiol 1987; 132: 143-8.

19. Coughlin SR, Barr PJ, Cousens LS, Fretto LJ, Williams LT. Acidic and basic fibroblast growth factors stimulate tyrosine kinase activity in vivo. J Biol Chem 1988; 263: 988-93.

20. Pollak M, Richard M. Suramin blockade of insulin-like growth factor I-stimulated proliferation of human osteosarcoma cells. J Natl Cancer Inst 1990; 82: 1349-52.

21. Baumann H, Strassmann G. Suramin inhibits the stimulation of acute phase plasma protein genes by IL-6-type cytokines in rat hepatoma cells. J Immunol 1993; 151: 1456-62.

22. Hensey CE, Boscoboinik D, Azzi A. Suramin, an anti-cancer drug, inhibits protein kinase C and induces differentiation in neuroblastoma cell clone NB2A. FEBS Lett 1989; 258: 156-8.

23. Kopp R, Pfeiffer A. Suramin alters phosphoinositide synthesis and inhibits growth factor receptor binding in HT-29 cells. Cancer Res 1990; 50: 6490-6.

24. Tsiquaye K, Zuckerman A. Suramin inhibits duck hepatitis B virus DNA polymerase activity. J Hepatol 1985; 1: $663-9$.

25. Bojanowski K, Lelievre S, Markovits J, Couprie J, Jacquemin-Sablon A, Larsen AK. Suramin is an inhibitor of DNA topoisomerase II in vitro and in Chinese hamster fibrosarcoma cells. Proc Natl Acad Sci USA 1992; 89 : 3025-9.

26. De Clercq E. Suramin: a potent inhibitor of the reverse transcriptase of RNA tumor viruses. Cancer Lett 1979; 8: 9-22.

27. Minniti CP, Maggi M, Helman LJ. Suramin inhibits the growth of human rhabdomyosarcoma by interrupting the insulin-like growth factor II autocrine growth loop. Cancer Res 1992; 52: 1830-5. 
28. Shiao RT, Miglietta L, Khera SY, Wolfson A, Freter CE. Dexamethasone and suramin inhibit cell proliferation and interleukin-6-mediated immunoglobulin secretion in human lymphoid and multiple myeloma cell lines. Leuk Lymphoma 1995; 17: 485-94.

29. Berns EM, Schuurmans AL, Bolt J, Lamb DJ, Foekens JA, Mulder E. Antiproliferative effects of suramin on androgen responsive tumor cells. Eur J Cancer 1990; 26: 470-4.

30. Vignon F, Prebois C, Rochefort H. Inhibition of breast cancer growth by suramin. J Natl Cancer Inst 1992; 84: $38-42$.

31. Hosang M. Suramin binds to platelet-derived growth factor and inhibits its biological activity. J Cell Biochem 1985; 29: 265-73.

32. Foekens JA, Sieuwerts AM, Stuurman-Smeets EM, Dorssers LC, Berns EM, Klijn JG. Pleiotropic actions of suramin on the proliferation of human breast-cancer cells in vitro. Int J Cancer 1992; 51: 439-44.

33. Cardinali M, Sartor O, Robbins KC. Suramin, an experimental chemotherapeutic drug, activates the receptor for epidermal growth factor and promotes growth of certain malignant cells. J Clin Invest 1992; 89: 1242-7.

34. Asada Y, Tsuneyoshi A, Marutsuka K, Sumiyoshi A. Suramin inhibits intimal thickening following intimal injury in the rabbit aorta in vivo. Cardiovasc Res 1994; 28: 1166-9.

35. Gray TJ, Strauss BH, Hinek A. Inhibitory mechanisms by which suramin may attenuate neointimal formation after balloon injury. J Cardiovasc Pharmacol 1999; 33: 960-71.

36. Edwards G, Breckenridge AM. Clinical pharmacokinetics of anthelmintic drugs. Clin Pharmacokinet 1988; 15: 67-93.

37. Gagliardi AR, Taylor MF, Collins DC. Uptake of suramin by human microvascular endothelial cells. Cancer Lett 1998; 125: 97-102. 